\title{
Clarification: Surnames and Social Mobility in England
}

\author{
Gregory Clark ${ }^{1} \cdot$ Neil Cummins ${ }^{2}$
}

Published online: 27 March 2015

(C) Springer Science+Business Media New York 2015

The authors of "Surnames and Social Mobility, 1170-2012," Human Nature, 25(4):517-537 (2014) wish to make the following clarification. The value for the heritability of height reported in fn. 1 (p.518), 0.64 , refers to the value reported in table 1 of James A. Hanley's (2004) “Transmuting women into men: Galton's family data on human stature," The American Statistician, 58(3):237-243. That paper is a reanalysis of Francis Galton's (1886) "Regression towards mediocrity in hereditary stature," Journal of the Anthropological Institute of Great Britain and Ireland, 15, 246-263. The citation we used in our Human Nature paper (Silventoinen et al. 2003) is incorrect as it refers to a wide range of studies with different methods and is not necessarily directly comparable with the Clark-Cummins study. We thank an anonymous referee for pointing this out.

This is a clarification with regard to the article available at http://dx.doi.org/10.1007/s12110-014-9219-y.

\section{Gregory Clark}

gclark@ucdavis.edu

Neil Cummins n.j.cummins@lse.ac.uk

1 Department of Economics, University of California, Davis, CA 95616, USA

2 Department of Economic History, London School of Economics, London WC1N 2AB, UK 